\title{
Rh Immune Globulin Administration
}

National Cancer Institute

\section{Source}

National Cancer Institute. Rh Immune Globulin Administration. NCI Thesaurus. Code C92947.

The administration of Rh Immune Globulin to a pregnant mother to ameliorate the effects of conflicting Rh factors during pregnancy. 